\title{
Designing 3-Dimensional In Vitro Oviduct Culture Systems to Study Mammalian Fertilization and Embryo Production
}

\author{
Marcia A. M. M. Ferraz, ${ }^{1}$ Heiko H. W. Henning, ${ }^{2}$ Tom A. E. Stout, ${ }^{1,2}$ Peter L. A. M. Vos, ${ }^{1}$ \\ and Bart M. GADELla ${ }^{1,3}$ \\ ${ }^{1}$ Department of Farm Animal Health, Faculty of Veterinary Medicine, Utrecht University, Yalelaan 104, 3584CM Utrecht, \\ The Netherlands; ${ }^{2}$ Department of Equine Sciences, Faculty of Veterinary Medicine, Utrecht University, Yalelaan 112, \\ 3584CM, Utrecht, The Netherlands; and ${ }^{3}$ Department of Biochemistry and Cell Biology, Faculty of Veterinary Medicine, \\ Utrecht University, Yalelaan 79, 3584CM Utrecht, The Netherlands
}

(Received 29 September 2016; accepted 4 November 2016; published online 14 November 2016)

Associate Editor Christiani Amorim oversaw the review of this article.

\begin{abstract}
The oviduct was long considered a largely passive conduit for gametes and embryos. However, an increasing number of studies into oviduct physiology have demonstrated that it specifically and significantly influences gamete interaction, fertilization and early embryo development. While oviduct epithelial cell (OEC) function has been examined during maintenance in conventional tissue culture dishes, cells seeded into these two-dimensional (2-D) conditions suffer a rapid loss of differentiated OEC characteristics, such as ciliation and secretory activity. Recently, threedimensional (3-D) cell culture systems have been developed that make use of cell inserts to create basolateral and apical medium compartments with a confluent epithelial cell layer at the interface. Using such 3-D culture systems, OECs can be triggered to redevelop typical differentiated cell properties and levels of tissue organization can be developed that are not possible in a 2-D culture. 3-D culture systems can be further refined using new micro-engineering techniques (including microfluidics and 3-D printing) which can be used to produce 'organs-on-chips', i.e. live 3-D cultures that biomimic the oviduct. In this review, concepts for designing biomimic 3-D oviduct cultures are presented. The increased possibilities and concomitant challenges when trying to more closely investigate oviduct physiology, gamete activation, fertilization and embryo production are discussed.
\end{abstract}

Keywords-3-D culture, Microfluidics, Bio-engineering, Fallopian tube, Polarized epithelium, Embryo development.

\begin{tabular}{ll} 
& \multicolumn{1}{c}{ ABBREVIATIONS } \\
2-D & Two-dimensional \\
3-D & Three-dimensional \\
ARTs & Assisted reproductive techniques \\
BM & Basal membrane \\
COC & Cumulus oocyte complex \\
EGF & Endothelial growth factor \\
ESR1 & Estrogen receptor 1 \\
FCM & Fluorescent confocal microscopy \\
FGF-10 & Fibroblast growth factor 10 \\
FOXJ1 & Forkhead box protein 1 \\
GJ & Gap junctions \\
GPX4 & Glutathione peroxidase 4 \\
HSB90B1 & Heat shock protein 90 beta member 1 \\
ICSI & Intracytoplasmic sperm injection \\
IVP & In vitro embryo production \\
MUC16 & Mucin 16 \\
OEC & Oviduct epithelial cells \\
OVGP1 & Oviductal glycoprotein 1 \\
PAX8 & Paired box 8 \\
PGR & Progesterone receptor \\
TGF- $\beta$ & Transforming growth factor beta
\end{tabular}

\section{THE OVIDUCT}

The oviduct, or fallopian tube, was first described by Fallopius in 1561 as a presumably passive channel to hold or transport gametes and early embryos in mammals. ${ }^{75}$ The oviduct is a convoluted tube consisting of longitudinal and circular muscular, and a 
stromal layer lined by a simple cuboidal to columnar epithelium containing both ciliated and secretory cells. ${ }^{83,106,123}$ The ciliated cells are important for gamete transport and sperm interaction, in particular helping to create a 'sperm reservoir'; while the secretory cells are responsible for producing oviduct fluid; a mixture of specific cell secretions and serum transudate. ${ }^{1,2,10,63,118}$ In adult mammals (including the woman), four anatomical segments can be distinguished along the length of the oviduct; the infundibulum, ampulla, isthmus and utero-tubal junction, respectively $^{11,122}$ (Fig. 1c). The fimbriae of the infundibulum are responsible for capturing the cumulus oocyte complex (COC) and ensuring its transport from the ovary into the oviductal tube. The epithelium of the ampulla is highly folded, has the largest diameter of any oviductal segment and is the specific site where fertilization takes place ${ }^{1}$ (Fig. 1b). The ampulla connects to the much narrower isthmic tube (Fig. 1a). Prior to fertilization, sperm entering the oviductal isthmus from the uterus bind to isthmic epithelial cells which help to prolong sperm viability (the formation of a so called "sperm reservoir"). ${ }^{19,96,108,112}$ A limited number of these bound sperm will be released at around the time of ovulation, undergoing the final changes required to achieve fertilizing capacity as they do so, and migrate into the ampullary region ${ }^{12}$ where they will encounter the mature oocyte (Fig. 1c). After fertilization, the developing embryo will migrate along the isthmic tube towards the utero-tubal junction. At the morula (16 cell) stage, the embryo will exit the oviduct and enter the uterine lumen (Fig. 1c), where it will develop further and undergo a series of complicated interactions with the endometrium in preparation for implantation. The oviductal vasculature is composed of branches of the uterine and ovarian arteries and veins, allowing local exchange of metabolites, hormones and signaling molecules between the oviduct, uterus and ovary. ${ }^{75}$

The oviduct is an active organ that orchestrates dynamic changes in its luminal fluid composition to provide optimal microenvironments for gamete maturation/activation, fertilization and early embryo development. ${ }^{64}$ It is the first environment to which an embryo is exposed, and contributes vital factors that affect embryonic development and help atune it to predicted external environmental circumstances during the first 2-6 days post-fertilization, depending on the species $^{50,115}$ (Table 1). The successful development of conditions for in vitro production (IVP) of embryos for various species has in part been the reason for the relative neglect of the importance of the oviductal microenvironment in early development. ${ }^{76}$ That the oviduct could be successfully by-passed supported the supposition that it was little more than a passive tube for temporarily hosting gametes and embryos. ${ }^{76} \mathrm{Nev}-$ ertheless, it has become clear that not only are fertilization and embryo development less efficient in vitro than in vivo, but the embryos produced are qualitatively different; a number of studies have now demonstrated the importance of the oviduct for sperm storage and activation, 23,32,44,50,53,60,61,73,74,81,91,92,95 oocyte modification, ${ }^{17,35,38,80}$ fertilization and early embryo development ${ }^{6,33,36,38,68,70,79,97,117}$ (Fig. 2a).

\section{STUDYING OVIDUCT FUNCTION}

Due to its intra-abdominal location, it is difficult to access the delicate interior of the oviduct for experimental studies in situ. It is possible to ligate and excise the oviduct from experimental animals and given reproductive stages and to fix the tissues for histological or other microscopic investigation. ${ }^{13,40}$ It is also possible to harvest epithelial cells from recovered oviducts. Methods to culture these oviduct epithelial cells (OEC) can differ with respect to cell isolation techniques, culture conditions and duration, medium used and supplements included. ${ }^{115}$ The aim of the present review is to describe how 3-D culture systems can be designed and modified such that contained OECs mimic their in vivo physiology as closely as possible. In this respect, the OECs should at least have a similar morphological appearance and differentiation characteristics and be connected to neighboring cells by tight junctions to form a confluent epithelial cell monolayer. The OECs should also resemble in vivo oviduct epithelial cells with respect to protein expression, ciliary and secretory activity, and responses to physiological stimuli. ${ }^{115}$

An ideal in vitro oviduct model should at least allow the possibility to mimic the hormonal changes that occur in the afferent vasculature in the lead up to, and following, ovulation. Moreover, the system should allow the addition and removal of fluids and gametes into the luminal compartment, promote fertilization and allow the culture of embryos to at least the compact morula stage of development (Fig. 2b). These conditions cannot be met when oviduct epithelial cells are simply plated into a petri dish or a cell culture flask. When oviduct epithelial cells are grown in such 2-D cultures they rapidly dedifferentiate into flattened cells without cilia or secretory activity, and also almost completely lose the ability to bind sperm ${ }^{104}$ or to promote fertilization in vitro. ${ }^{72}$ Interestingly, with the aid of cell inserts separate compartments (conform Fig. 3) can be created since the medium in the culture dish is separated from the medium in the cell insert, resulting in a basolateral (petri dish) and an apical (cell insert) compartment. OECs can be cultured to con- 
(a)

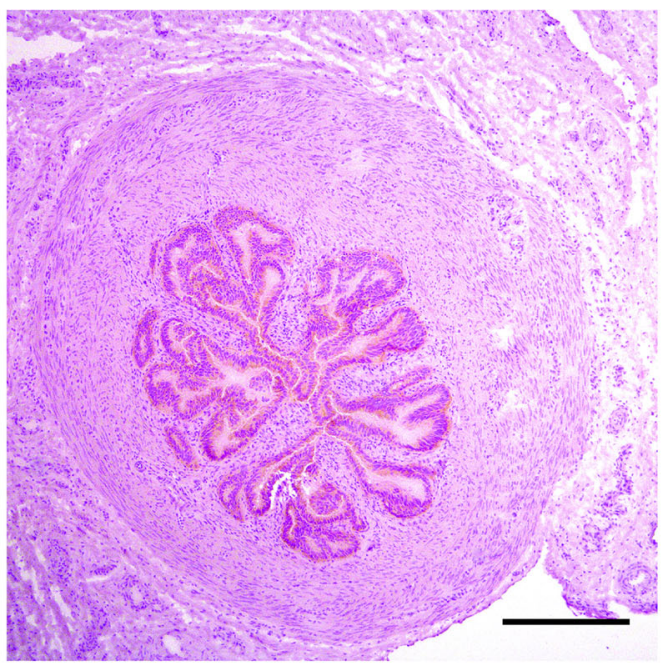

(b)

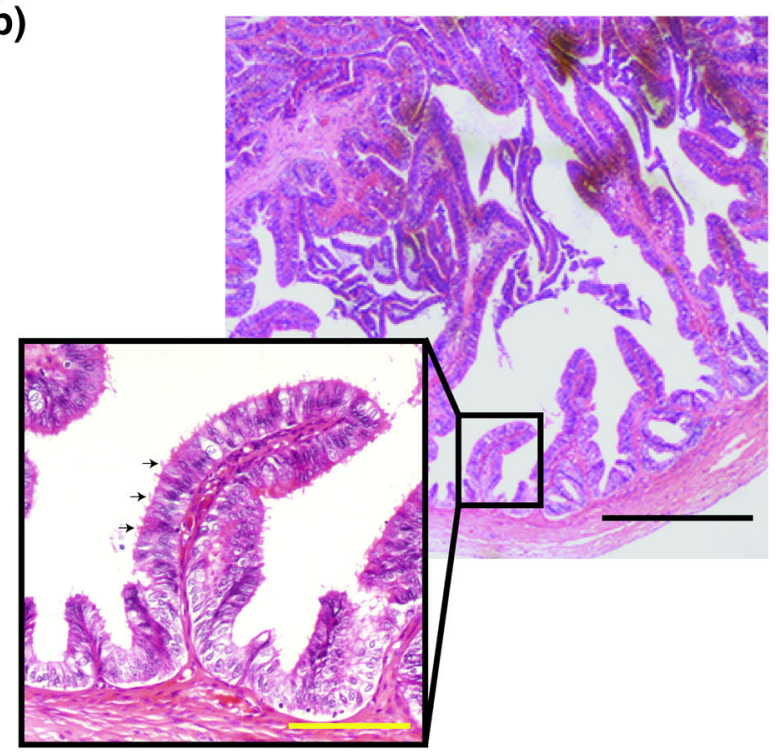

(c)

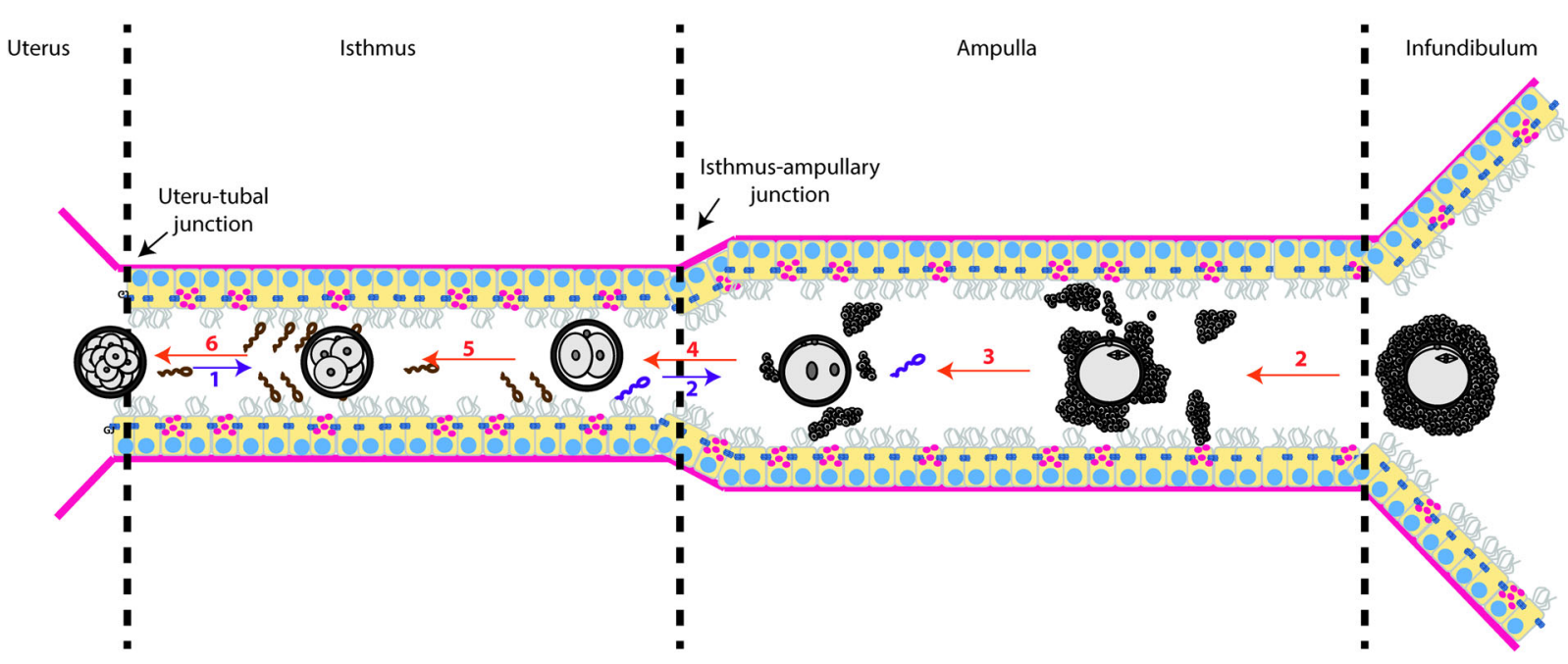

FIGURE 1. Histological images from bovine oviduct sections of (a) the isthmus (b) the ampulla (with an enlargment of a folded area to show the organization of the cuboid to columnar epithelial cells; black arrows indicate ciliated cells). Note the thicker stroma and muscular wall, and smaller lumen, of the isthmus (a) compared to the ampulla (b), and the higher degree of folding of the ampulla. (c) A schematic view of the entire length of the oviduct including the different segments: the utero-tubal junction, the isthmus, the isthmus-ampullary junction, the ampulla and the infundibulum, respectively. In this schematic view, the various reproductive processes are listed in chronological and spatial order: (1) entry of sperm from the uterine lumen and establishment of a sperm reservoir in the isthmus; (2) at the time of ovulation, the released COC will be captured by the infundibulum, and biochemical changes in the oviduct milieu will stimulate sperm release form the reservoir, and migration to the site of fertilization; (3) the COC will be transported through the ampulla and fertilized by one of the capacitated spermatozoa while, during transport, the COC will gradually lose its cumulus mass; (4) the fertilized oocyte (zygote) will continue its development until the first cell cleavage event; (5) the 2-cell embryo, and after successive cleavages 4,8 and 16 cell stages are formed (the latter is termed a morula); (6) the morula stage leaves the oviduct via the UTJ and will develop further and implant within the uterus. Black bars $=50$ $\mu \mathrm{m}$, yellow bar $=10 \mu \mathrm{m}$.

fluence on the cell insert and by removing the medium in the insert an air-liquid interface is created that induces the OECs to establish polarity comparable to that seen in situ in the oviduct and to differentiate into active secretory and ciliated cells. ${ }^{13,14,34,39,77,90,93}$

Interestingly, there are no reports of embryo production in these 3-D cell insert-based OEC systems, presumably at least in part because in the insert filters, on which the epithelial cells grow, neither the medium in the petri dish nor that in the cell insert can be perfused to mimic the endocrine changes that will in turn influence OEC function during the peri-ovulatory period. A number of recently introduced technologies may help overcome these short comings: (1) advances in three-dimensional (3-D) printing within biomedical engineering have allowed the creation of scaffolds for 
(a)

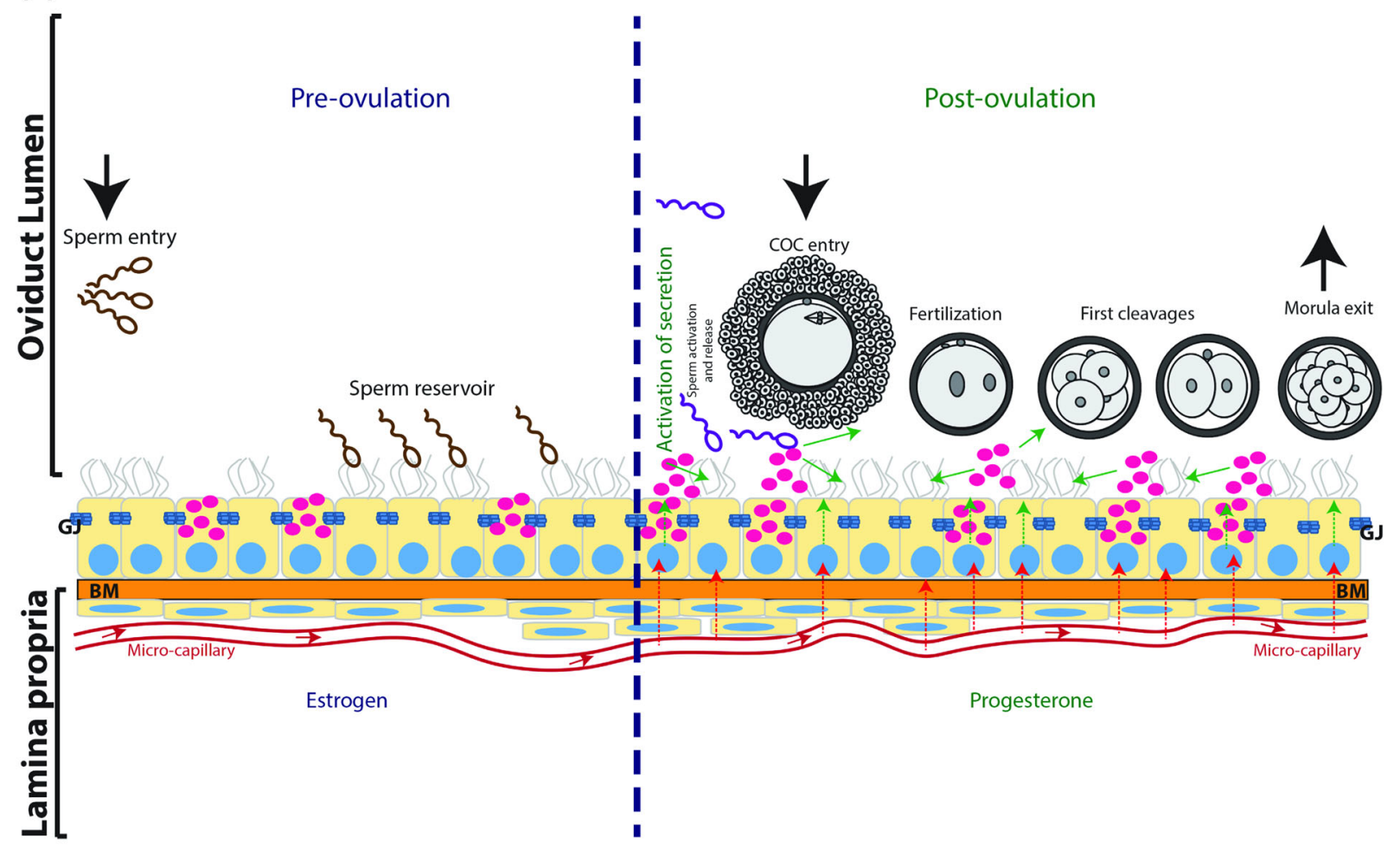

(b)
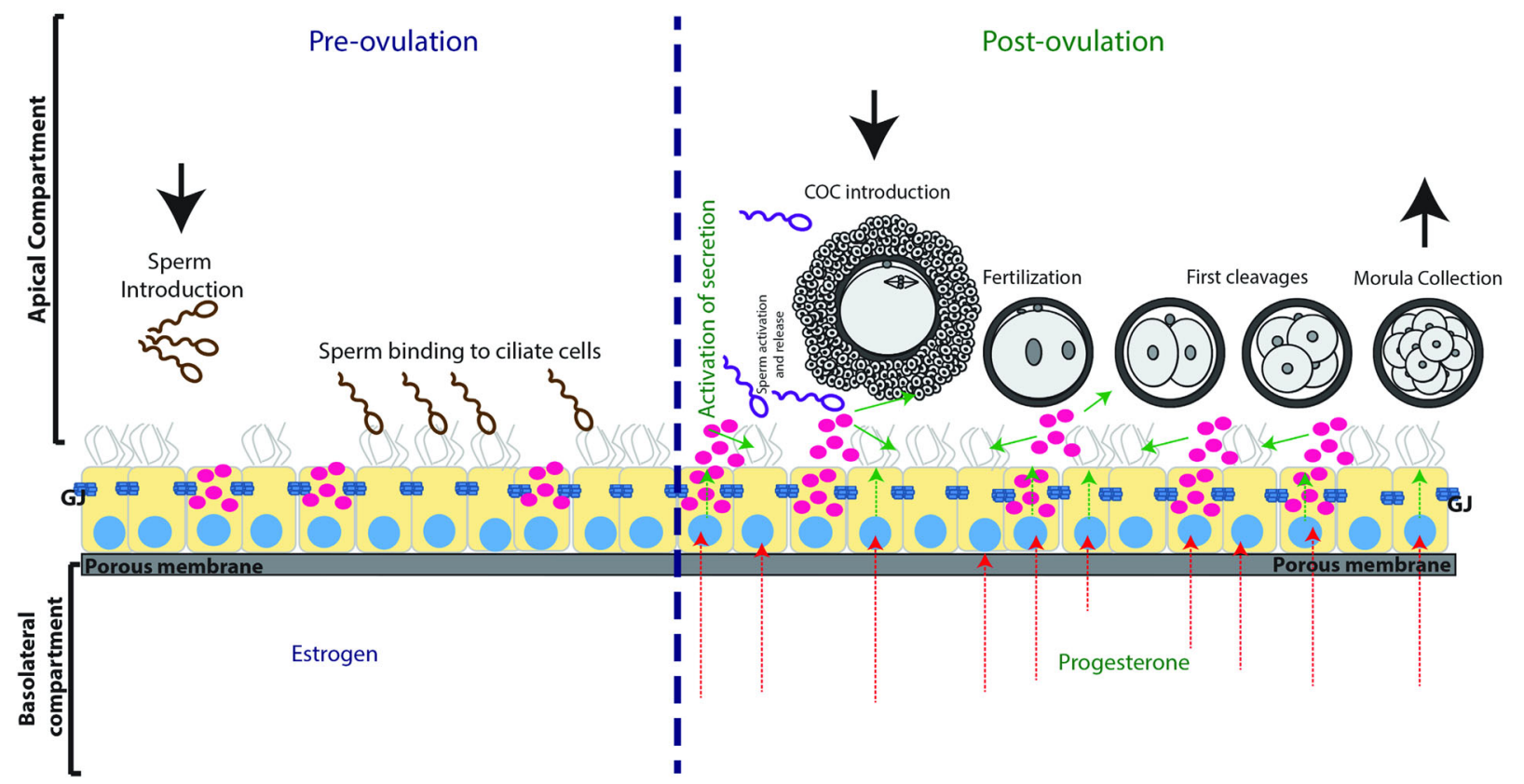
4FIGURE 2. Schematic representation of the oviduct, including its microenvironment before and after ovulation, and of the ideal in vitro model of the oviduct. (a): the oviduct epithelium consists of ciliated and non-ciliated (secretory) cells held together in a confluent monolayer of communicating cells by gap junctions (GJ). This epithelium is attached to the luminal side of the basal membrane (BM) which is, in turn, connected to the stroma (containing fibroblast cells and endothelial blood supply) at its peripheral side. Sperm can enter the oviduct and bind to the ciliated cells. This results in the formation of a sperm reservoir during the pre-ovulatory period, under the influence of elevated circulating estrogen concentrations. Ovulation coincides with a switch in endocrine environment in the capillary blood flow of the oviduct. This change stimulates secretory activity in the oviduct epithelium which triggers the release of bound sperm from the isthmus, aids capture of the cumulus-oocyte-complex (COC) and migration of sperm into the ampulla of the oviduct. In the post-ovulatory period, the oviduct is under the influence of progesterone which should promote fertilization and embryo development to the morula stage, when the embryo is ready to leave the oviduct and enter the uterus for further development and implantation. (b) A separation of two compartments with a porous filter, apical reservoir (medium inside the insert) and basolateral reservoir (medium in petri dish), is necessary to mimic the oviduct lumen and lamina propria of the in vivo oviduct, respectively (conform (a)). The double perfusion system can be used to simulate peri-ovulatory changes in the blood supply (in the basolateral compartment) and introduce gametes and collect embryos, as would take place in the oviduct in vivo (a).

TABLE 1. Embryo development within the oviduct of different species (timing is recorded as days after fertilization)

\begin{tabular}{lllll}
\hline Species & 2-cells & 4-cells & 8-cells & Morula \\
\hline Woman & 1.5 days & 2 days & 3 days & 4 days \\
Cow & 1.5 days & 2 days & 2.5 days & 3.5 days \\
Sow & $0.75 \mathrm{~h}$ & 1.5 days & 2 days & 4.5 days \\
Mare & 1 day & 1.5 days & 3 days & 5.5 days \\
Ewe & 1 day & 1.5 days & 2 days & 3 days \\
Mouse & 1.5 days & 2 days & 2.5 days & 3 days \\
\hline
\end{tabular}

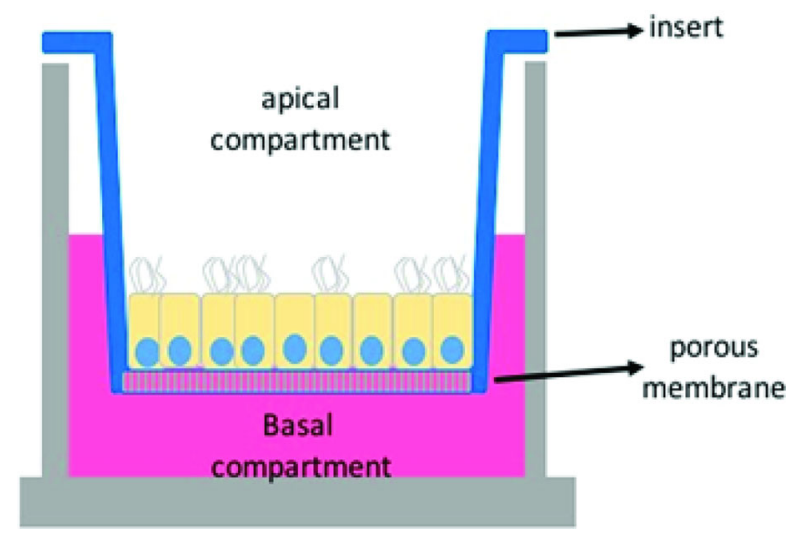

FIGURE 3. Porous membrane cell culture inserts. In this culture system two compartments are formed (apical and basolateral) that are separated by a porous membrane and a confluent layer of oviduct epithelial cells. This cell culture insert only allows static fluid culture. live cells, microfluidic devices, and tools for medical imaging. ${ }^{69}$ Since the technology allows rapid printing of prototypes directly from computer-based designs, it is possible to quickly (hours or days) produce novel devices on demand. ${ }^{69}$ The typical folding of the oviduct epithelium (Fig. 1) could be mimicked using these modern 3-D printing approaches. (2) More accurate and miniaturized cell perfusion systems are being developed using microfluidic circuits. When microperfusion of both the basolateral (petri dish) and apical (insert) compartments can be achieved, this will mimick the peri-ovulatory hormone changes while simultaneously permitting introduction and collection of gametes and embryos, and sampling of cell secretions. Combining these technologies could result in the creation of a reliable in vitro oviduct model to study gamete activation, gamete interaction, fertilization, early embryo development and in vitro embryo production. Ultimately, it would be hoped that the embryos produced would be more similar to in vivo embryos than IVP embryos produced using current systems. In the following sections, the differences between current OEC culture systems are described in more detail. The type of information that can be gathered from each approach, and their shortcomings, are dealt with. These are further discussed with respect to the anticipated requirements when designing new 3-D culture systems for enhanced gamete maturation, fertilization and early embryo production.

\section{APPROACHES TO STUDY OVIDUCT FUNCTION}

In vivo and Ex Vivo

In situ research of oviduct function is difficult due to its intra-abdominal location and tortuous morphology. A single study has reported in vivo imaging of prelabeled sperm cells in the oviduct, using fibered fluorescent confocal microscopy (FCM) in the ewe. ${ }^{26}$ FCM allowed individual spermatozoa to be observed with high resolution in situ in the female genital tract, and moreover to quantitatively track their transit through the uterus and entrance into the oviduct. ${ }^{26}$

Most investigations of oviduct function described as "in vivo" are actually ex vivo experiments, because the organ was first removed from the animal. These studies are also not entirely in vitro because the organ, or at least a part of it, is intact. ${ }^{116}$ Usually, such ex vivo intact organ experiments are hampered by a rapid loss of cell viability, which significantly limits the duration of any experiments (several minutes to a few hours). Nevertheless, ex vivo organ incubations have been widely used to study sperm migration through the oviduct by video microscopy ${ }^{57-59,103,107,108}$ and epiflu- 

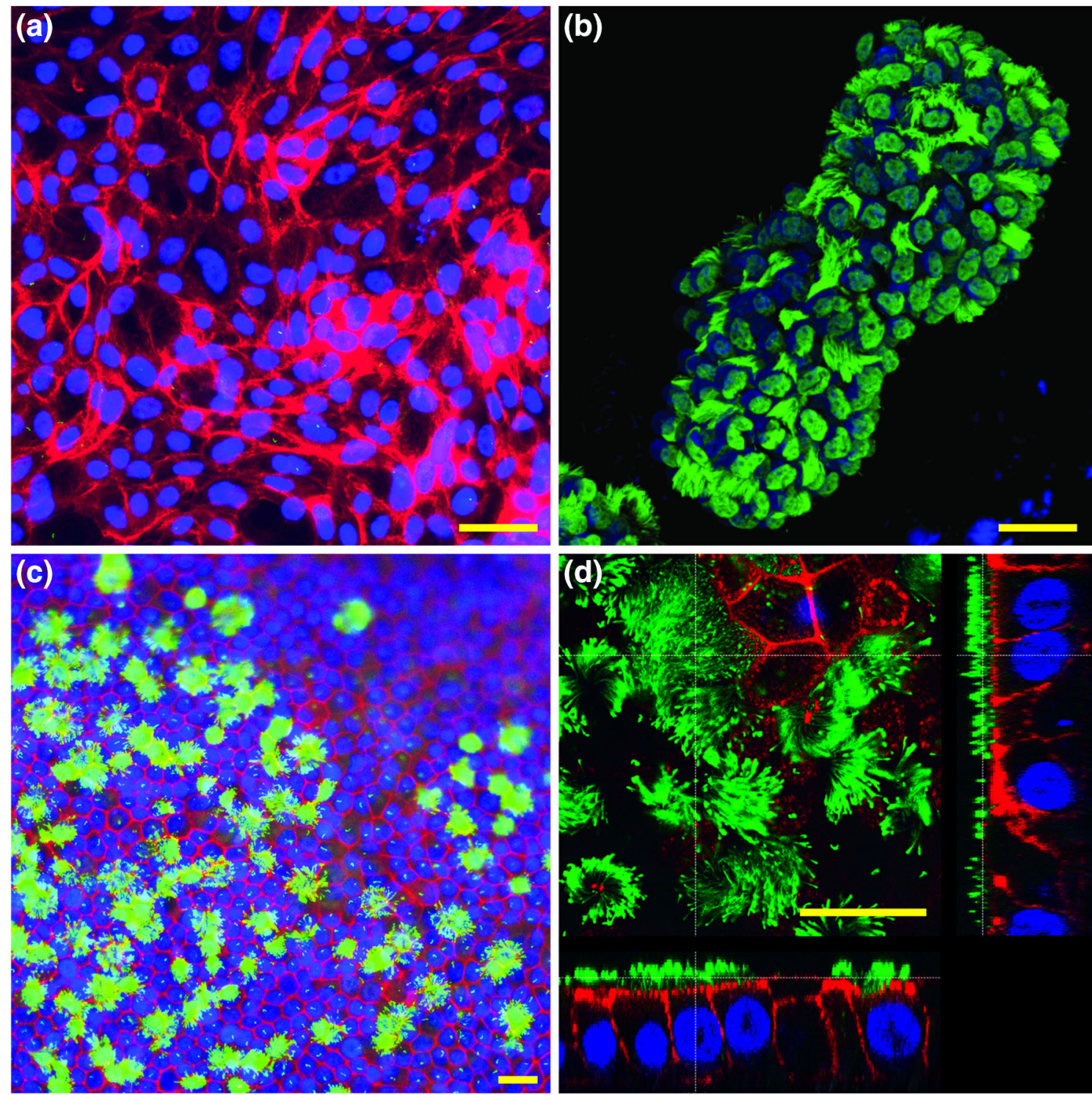

FIGURE 4. Fluorescent staining for nuclei (blue, Hoechst33342), actin filaments (red, phalloidin) and cilia (green, indirect immunofluorescent labeling of acetylated alpha tubulin) in different in vitro oviduct epithelial cell (OEC) culture techniques. (a) An equine 2-D OEC culture without secondary cilia. (b) A bovine OEC explant vesicle showing ciliated and non-ciliated cells (note; we did not stain this specimen for phalloidin as confluent contact between the cells in this epithelial vesicle is known to remain intact). (c) and (d) Equine OECs cultured on porous membranes for 6 weeks at an air-liquid interface; note the presence of ciliated and nonciliated cells in C and D, and the columnar shape of the cells with nuclei at the base and cilia at the apical aspect of the cells in $D$. Equine images were provided by H.H.W.H (data unpublished) and bovine image by M.A.M.M.F. (data unpublished). Bars $=25 \mu \mathrm{m}$.

orescence microscopy. ${ }^{61}$ These techniques are especially applicable to species, like the hamster and the mouse, with a transparent wall to the ampullary region or entire oviduct. ${ }^{107}$ However, ex vivo approaches are further limited in that they allow only the imaging of physically detectable changes, such as cilia beating and gamete/embryo movement within the oviduct. In addition, the imaging must be done after collecting the oviducts post-mortem or after surgical removal or by using laparoscopy under general anesthesia, all of which are laborious and invasive procedures.

\section{In Vitro}

The most commonly reported method for investigating oviduct function in vitro oviduct is the monolayer culture (2-D culture; Fig. 4a). 2-D culture of OECs is hampered by a rapid loss of typical differentiated OEC properties, such as ciliation, columnar cell morphology, cell polarity, secretory granules and bulbous protrusions. ${ }^{8,39,40,47,48,101,104,115}$ The use of 2-D culture was nevertheless a useful first step in trying to understand the roles of the oviduct during gamete 
interaction and early embryo development. Even though OEC morphology is not preserved during 2-D culture, several studies demonstrated interactions between the OECs and spermatozoa, indicating that OECs and/or their secretions could influence sperm function. $^{29,30,81,112}$ Additionally, there is evidence of beneficial effects of OECs in 2-D culture on the early embryo via OEC-derived embryotrophic growth factors, ${ }^{114}$ a decreased oxygen tension and avoidance of the block to embryonic genome activation. ${ }^{28,37,84}$

Another in vitro model used to study gamete interaction and embryo development is the oviduct explants (Fig. 4b). Oviduct explants are aggregates of epithelial and stromal cells that organize to form motile, everted vesicles with active cilia on the outer surface. ${ }^{40,66,86}$ OECs in oviduct explants are able to maintain their differentiated morphology as characterized by secondary cilia, numerous mitochondria and rough endoplasmic reticulum, ${ }^{86}$ and expression of oviductal epithelial cell markers such as oviductal glycoprotein 1 (OVGP1), glutathione peroxidase 4 (GPX4) and forkhead box protein 1 (FOXJ1). ${ }^{71}$ One drawback at least for bovine material is the limited viability of the explants that, within hours to days, lose their differentiated state with the epithelial cells becoming flat and non-ciliated which appears not to be such a problem for equine material. ${ }^{66,86}$ Another disadvantage is the fact that the system doesn't mimick the air-liquid interface as it happens in vivo needing a large volume of medium during culture, therefore not mimicking oviductal conditions properly.

Three-dimensional culture using inserts with porous membranes and air-liquid interfaces (Figs. 3c and 3d) have been developed in recent years. This technique allows cultured OECs to retain their polarized columnar epithelial cell characteristics, and has been applied successfully to OECs from various mammalian species. ${ }^{14,16,34,40,92-94}$ Within the inserts, seeded OECs first form a confluent layer on the porous membrane. Subsequently, the medium from the apical aspect is removed to establish an air-liquid interface. As a result, the cells receive metabolites only from the basal surface, a trick that induces apical-basolateral polarity. Moreover, the OECs start to re-differentiate and begin to express secondary cilia on their apical surface from 2-3 weeks post-confluence and are able to maintain the polarized state during long term culture (for at least 6 more weeks). The resulting polarized OECs are able to bind introduced sperm ${ }^{13,40,92}$ and secrete factors into medium film of the insert that triggers the release of previously bound sperm. ${ }^{40}$ Moreover, the OECs are responsive to endocrine stimulation, as demonstrated by an increase in the expression of prostaglandin receptor (PGR), estrogen receptor 1 (ESR1) and epithelial markers such as mucin 16 (MUC16), OVGP1 and heat shock protein 90 beta member 1 (HSB90B1), when exposed to estrogens, and a decrease in the same markers when stimulated by progesterone. ${ }^{13}$ Despite all the potential advantages of 3-D OEC cultures, current well inserts do not permit live imaging or perfusion studies. Moreover, theses 3-D OEC systems lack the tubular folded architecture of the oviduct. These shortcomings are likely to limit their use to study gamete interactions and early embryo development in any detail.

\section{Organoid Models}

Two different methods for developing oviduct organoids have been described ${ }^{49,54,55}$ and, in both, it was possible to maintain differentiated OECs within a folded tubular structure reminiscent of the in vivo oviduct: (1) In the first method, small pieces of oviduct were cultured inside an alginate matrix. These organoids were maintained in culture for 7 days and expressed normal oviductal epithelial cell markers, such as OVGP1, paired box 8 (PAX8), E-cadherin and cytokeratin; they also preserved a columnar epithelium with a mix of ciliated and non-ciliated cells. ${ }^{54}$ (2) The second method for organoid culture was based on the existence of adult stem cells in the distal part of the oviduct. ${ }^{49,88,89,120}$ Kessler and collaborators ${ }^{49}$ isolated these adult stem cells and cultured them in a Matrigel matrix supplemented with a cocktail of growth factors, including epidermal growth factor (EGF), fibroblast growth factor 10 (FGF-10) and transforming growth factor beta (TGF- $\beta)$. The cells were able to proliferate and form spheroids, with folds appearing during the second week of culture. The resulting organoids also presented highly polarized columnar epithelial cells orientated with the apical side into the sphere's lumen. The mature organoids presented both PAX-8 positive secretory cells and PAX-8 negative, but acetylated tubulin positive, ciliated cells and were able to maintain this morphology during long term culture (up to 8 months). Demonstrating a fully differentiated epithelium, with both ciliated and secretory cells, that can communicate directly (by the interaction between the sperm cell and the cilia, the sperm reservoir) or indirectly (by secreting factors into its lumen) with gametes and embryos. Although organoid culture can preserve oviduct morphology and OEC polarization, it has limitations in that the luminal compartment of the organoid is only accessible for gametes or embryos via micro-puncturing. Thus, expensive micromanipulators are required and technical expertise must be developed to further study gamete activation, fertilization and embryo development. 

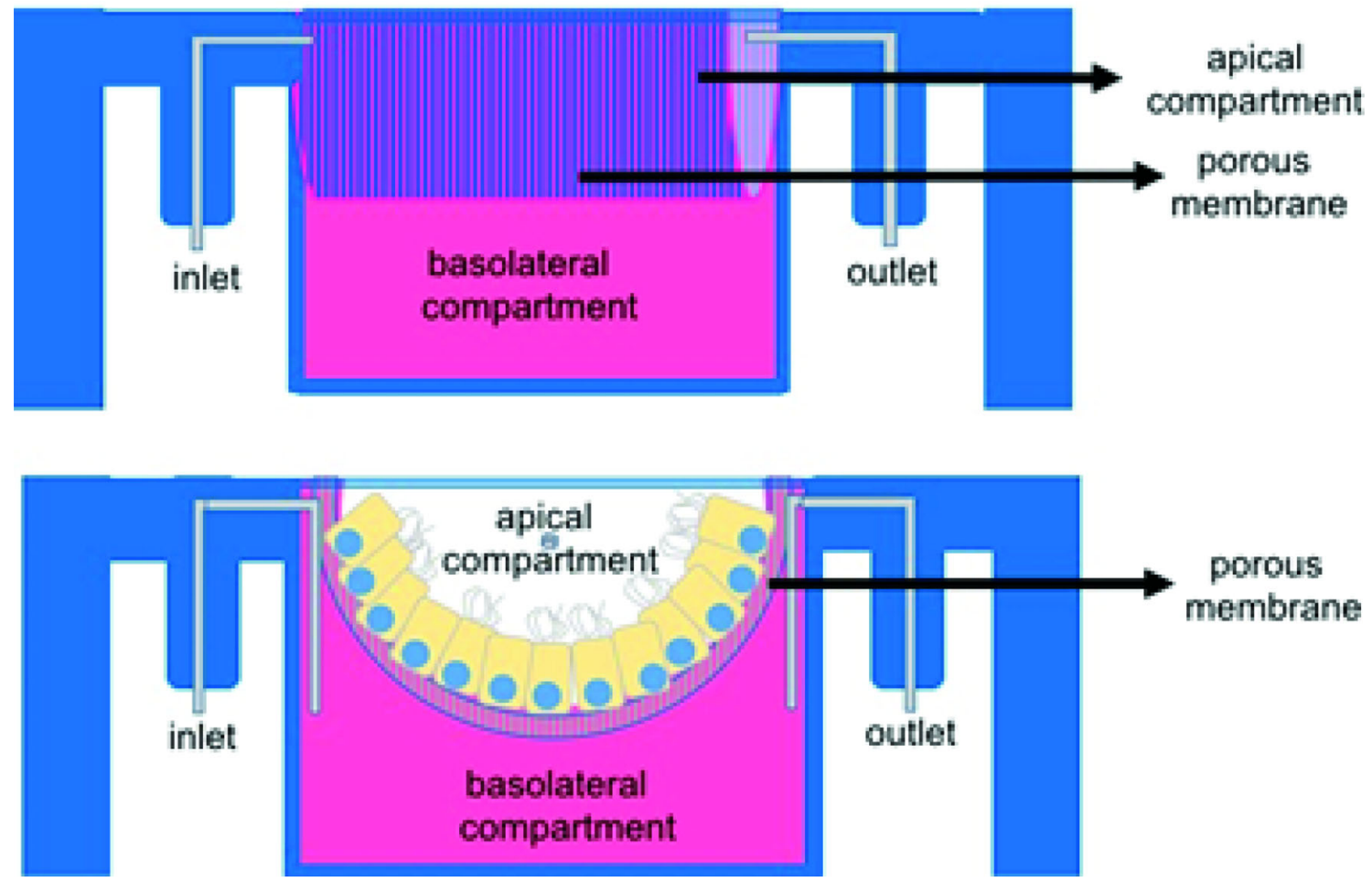

FIGURE 5. The 3-D printed oviduct-on-a-chip cultures. Also in this culture systems two compartments are formed (apical and basolateral) that are separated by a porous membrane and a confluent layer of oviduct epithelial cells. Note the inlets and outlets for independent perfusion of the apical and basolateral compartments, and the folded U-shape structure, that are introduced into the 3-D printed oviduct-on-a-chip.

\section{Microfluidics}

Research into microfluidics and reproductive events have increased in the past years, and relatively new papers on microfluidics and gamete development have been published. ${ }^{4,15,20,21,24,31,41,42,52,56,62,78,99,111,121,124}$ In most cases, these papers relate to sperm migration, and none have included OECs in the model. Interestingly, microfluidics devices have been designed to study sperm rheotaxis, movement, thermotaxis and chemotaxis, thereby mimicking physical and chemical factors that sperm encounter during their passage through the female tract (for a detailed description see Suarez and $\mathrm{Wu}^{109}$ ). Zhang and collaborators ${ }^{124}$ included oviductal fluid to help select sperm cells via a microfluidics system. Using this combination, they were able to observe sperm migration and select sperm with better motility and DNA integrity, concluding that it was a useful tool for selecting sperm for IVF procedures. It was also demonstrated that sperm rely more on the channel geometry than chemotaxis (i.e. sperm cells preferentially swim along boundaries and, when two boundaries intersect, the cells will follow the corner, swimming along one-dimensional folds ${ }^{24}$ ). Although the folding of the oviduct is more complex than the walls of a fabricated microchannel, these results suggest that the 3-D architecture of the compartment in which sperm migrate is important and that the topography of the oviduct wall may help guide the spermatozoa to the oocyte in vivo. ${ }^{24}$

Angione and collaborators ${ }^{4}$ engineered a microfluidic device that allows precise and flexible handling of individual oocytes and embryos. Their system allowed perfusion and live imaging of the introduced oocytes or developing embryos that could be used for both clinical and research IVF purposes. Nevertheless, most current embryo culture systems are static, ${ }^{111}$ although interest in microfluidic devices for embryo culture systems has increased in recent years. Potential benefits of a dynamic (microfluidic) embryo culture system are continuous removal of harmful products and replenishment of substrates, disruption of unwanted environmental gradients, physical stimulation and activation of signaling pathways. ${ }^{111}$ Mechanical stimulation of bovine embryos in a microfluidic device increased the proportion of 2-cell embryos developing into 8-cell embryos, when a constrictive channel was used (increasing from 23.9 to $56.7 \%$ ). ${ }^{52}$ Mechanical shear stresses imposed should not however be too harsh because embryos degenerate at values above $1.2 \mathrm{dyn} / \mathrm{cm} .{ }^{2121} \mathrm{~A}$ "womb-on-a-chip" was designed to 
establish a dynamic co-culture between endometrial cells and the embryo. ${ }^{78}$ This system allows investigation of the interaction between the embryo and secretions from the endometrial cells, moreover the coculture resulted in improved murine blastocyst rates. ${ }^{78}$ Nevertheless, a similar approach using microfluidics combined with OECs to enhance embryo production has not yet been reported.

\section{3-D Printing}

Micro-engineered 3-D cell cultures, in which cells are maintained in micro-3-D fabricated devices that mimic tissue- and organ-specific micro-architecture, ${ }^{43}$ have recently attracted attention. These approaches promote levels of cell differentiation and polarization that are not readily achieved by normal 2-D cultures. Nowadays, 3-D printing offers a fast prototyping process technology, such that researchers can design and print devices in a short period of time ${ }^{69}$ Combined with microfluidics, these techniques can lead to rapid creation and refinement of organs-on-a-chip to study human and animal organ-specific physiology and may, thereby, offer better in vitro organ models for research into aspects of physiology, disease and toxicology. ${ }^{43}$

3-D printing has been used to fabricate various tissues including bone, cartilage, skin, heart tissue, and vascular tubes. ${ }^{82}$ To our surprise, we were the first to use 3-D printing technology in combination with microfluidics for assisted reproduction, when developing an oviduct-on-a-chip model. ${ }^{72} \mathrm{We}$ designed and 3-D printed, using the stereolithography technique, a tubular like insert in which OECs could be cultured at an air-liquid interface and acquire and maintain epithelial polarization and differentiated cell state during long-term culture. The 3-D culture and polarization of OECs in our 3-D printed inserts resembles that of the cell insert approach with porous membranes (Fig. 3). However with the new 3-D OEC system, live imaging is possible, sperm can bind to the apical side of the OEC and be released. Furthermore, the system promotes normal fertilization and is easy to manipulate (i.e. for adding or removing gametes, embryos and cell secretions). The system also allows independent double perfusion (i.e. of the apical and basolateral medium compartments independently; Fig. 5) while maintaining a tubular morphology that could be made more complex to better mimic the oviduct. Furthermore the cells can keep a polarized state for long term cultures (at least six weeks), without loosing ciliation and ability to promote sperm activation (Ferraz et al., unpublished results).

Therefore, the oviduct-on-a-chip is a step forward for mimicking the interaction between gametes and embryos and the maternal oviductal environment. This will yield a better and more accessible bio-mimicking tool to study oviduct physiology and improve understanding of reproductive health and disease, as well as for screening toxicological compounds and novel drugs.

\section{IMPROVEMENTS IN OVIDUCT MODELLING VIA BIOENGINEERING}

Better 3-D cell culture systems to bio-mimic the oviduct can help to improve our understanding of in vivo processes that take place in this organ, and should help to improve the efficacy of assisted reproductive technologies (ARTs). The oviduct has an essential function in guiding and regulating sperm activation, oocyte maturation, fertilization and early embryo development. ${ }^{28,38,51,68,91,114}$ A better understanding of how the oviduct orchestrates these processes could aid in the development of better sperm storage and cryopreservation techniques. ${ }^{25,105}$ Moreover, improved oocyte maturation and IVP results, including a reduction in polyspermic fertilization and parthenogenetic activation, can also be achieved. ${ }^{17,18,45,68,80}$ Another aspect of improved IVP embryo quality could be survival after cryopreservation, reduced lipid content and avoidance of epigenetic changes that can impair embryo development or offspring health. $5,7,9,22,27,46,67,87,97,98,100,113$ Conventional in vitro fertilization (IVF) and embryo production has species specific problems. For instance, equine oocytes cannot be fertilized in vitro unless intracytoplasmic sperm injection (ICSI) is used, which requires expensive and dedicated technology and is labour intensive. ${ }^{3,65,102}$ For cattle, it is known that IVP embryos are of lower quality and have reduced cryosurvival compared to embryos flushed from the uterus. ${ }^{85,110,119}$ Both examples, clearly indicate that the oviductal environment is more conducive to producing good quality embryos than any in vitro system tested to date. Future studies will reveal whether or not the oviducton-a-chip approach will offer a superior oviduct-like environment for improved embryo production. A working oviduct-on-a-chip system would also offer a novel approach to reproductive toxicology testing or pharmaceutical agent screening, and for male and female infertility testing.

As we move from 2-D cultures to micro-engineered organs-on-a-chip, new challenges will undoubtedly arise. For instance, optimizing biological (cell) and non-biological (materials) culture requirements, optimizing/allowing cell polarization, differentiation and preventing possible toxic effects of the materials used. A multidisciplinary approach will be necessary to solve the likely challenges and maximally exploit the new 
opportunities the organ-on-a-chip technique will offer. In the more distant future, more complex bioengineered tissues (such as multilayered oviduct, follicles and endometrial cell cultures) could be combined to create a female-reproductive-tract-on-a-chip. However, at present we believe that the oviduct-on-a-chip technology is closer to being ready, and has more obvious immediate applications in the field of ART.

\section{ACKNOWLEDGMENTS}

We would like to thank Edita Sostaric for providing the histological pictures of oviduct sections. We also thank Jos Malda and Pedro Ferreira da Costa, from the Biofabrication Facility of the Utrecht Medical Center, for their collaboration in developing the 3-D printed oviduct.

\section{OPEN ACCESS}

This article is distributed under the terms of the Creative Commons Attribution 4.0 International License (http://creativecommons.org/licenses/by/4.0/), which permits unrestricted use, distribution, and reproduction in any medium, provided you give appropriate credit to the original author(s) and the source, provide a link to the Creative Commons license, and indicate if changes were made.

\section{REFERENCES}

${ }^{1}$ Abe, H. The mammalian oviductal epithelium: regional variations in cytological and functional aspects of the oviductal secretory cells. Histol. Histopathol. 11:743-768, 1996.

${ }^{2} \mathrm{Abe}, \mathrm{H}$. Immunocytochemical evidence that a specialised region of the rat oviduct secretes an oviductal glycoprotein. J. Anat. 188(Pt 2):333-339, 1996.

${ }^{3}$ Alonso, A., C. Baca Castex, A. Ferrante, M. Pinto, C. Castañeira, V. Trasorras, M. C. Gambarotta, L. Losinno, and M. Miragaya. In vitro equine embryo production using air-dried spermatozoa, with different activation protocols and culture systems. Andrologia 47:387-394, 2015.

${ }^{4}$ Angione, S. L., N. Oulhen, L. M. Brayboy, A. Tripathi, and G. M. Wessel. Simple perfusion apparatus for manipulation, tracking, and study of oocytes and embryos. Fertil. Steril. 103:281-290, 2015.

${ }^{5}$ Arnaud, P., and R. Feil. Epigenetic deregulation of genomic imprinting in human disorders and following assisted reproduction. Birth Defects Res. Part C Embryo Today Rev 75(2):81-97, 2005.

${ }^{6}$ Besenfelder, U., V. Havlicek, and G. Brem. Role of the oviduct in early embryo development. Reprod. Domest. Anim. 47:156-163, 2012.
${ }^{7}$ Betsha, S., M. Hoelker, D. Salilew-Wondim, E. Held, F. Rings, C. Große-Brinkhause, M. U. Cinar, V. Havlicek, U. Besenfelder, E. Tholen, C. Looft, K. Schellander, and D. Tesfaye. Transcriptome profile of bovine elongated conceptus obtained from SCNT and IVP pregnancies. Mol. Reprod. Dev. 80:315-333, 2013.

${ }^{8}$ Betsha, S., M. Hoelker, D. Salilew-Wondim, E. Held, F. Rings, C. Große-Brinkhause, M. U. Cinar, V. Havlicek, U. Besenfelder, E. Tholen, C. Looft, K. Schellander, D. Tesfaye, E. Sostaric, S. J. Dieleman, C. H. A. van de Lest, B. Colenbrander, P. L. A. M. Vos, N. Garcia-Gil, and B. M. Gadella. Sperm binding properties and secretory activity of the bovine oviduct immediately before and after ovulation. Mol. Reprod. Dev. 80:315333, 2013

${ }^{9}$ Brezina, P. R., W. H. Kutteh, A. P. Bailey, J. Ding, R. W. Ke, and J. L. Klosky. Fertility preservation in the age of assisted reproductive technologies. Obstet. Gynecol. Clin. North Am. 42:39-54, 2015.

${ }^{10}$ Buhi, W. C., I. M. Alvarez, and A. J. Kouba. Secreted proteins of the oviduct. Cells Tissues Organs 166(2):165179, 2000.

${ }^{11}$ Burkitt, M., D. Walker, D. M. Romano, and A. Fazeli. Using computational modeling to investigate sperm navigation and behavior in the female reproductive tract. Theriogenology 77(4):703-716, 2012.

${ }^{12}$ Burkitt, M., D. Walker, D. M. Romano, and A. Fazeli. Computational modelling of maternal interactions with spermatozoa: potentials and prospects. Reprod. Fertil. Dev. 23:976-989, 2011.

${ }^{13}$ Chen, S., R. Einspanier, and J. Schoen. In vitro mimicking of estrous cycle stages in porcine oviduct epithelium cells: estradiol and progesterone regulate differentiation, gene expression, and cellular function. Biol. Reprod. 89:54, 2013.

${ }^{14}$ Chen, S., R. Einspanier, and J. Schoen. Long-term culture of primary porcine oviduct epithelial cells: validation of a comprehensive invitro model for reproductive science. Theriogenology 80:862-869, 2013.

${ }^{15}$ Cheng, S.-Y., S. Heilman, M. Wasserman, S. Archer, M. L. Shuler, and M. Wu. A hydrogel-based microfluidic device for the studies of directed cell migration. Lab Chip 7:763-769, 2007.

${ }^{16}$ Comer, M. T., H. J. Leese, and J. Southgate. Induction of a differentiated ciliated cell phenotype in primary cultures of Fallopian tube epithelium. Hum. Reprod. 13:31143120, 1998.

${ }^{17}$ Coy, P., and M. Avilés. What controls polyspermy in mammals, the oviduct or the oocyte? Biol. Rev. 85:593605, 2010.

${ }^{18}$ Coy, P., S. Cánovas, I. Mondéjar, M. D. Saavedra, R. Romar, L. Grullón, C. Matás, and M. Avilés. Oviductspecific glycoprotein and heparin modulate sperm-zona pellucida interaction during fertilization and contribute to the control of polyspermy. Proc. Natl. Acad. Sci. U. S. A. 105:15809-15814, 2008.

${ }^{19}$ Coy, P., F. A. Garcia-Vázquez, P. E. Visconti, and M. Avilés. Roles of the oviduct in mammalian fertilization. Reproduction 144(6):649-660, 2012.

${ }^{20} \mathrm{de}$ Wagenaar, B., J. T. W. Berendsen, J. G. Bomer, W. Olthuis, A. van den Berg, and L. I. Segerink. Microfluidic single sperm entrapment and analysis. Lab Chip 15:1294$1301,2015$.

${ }^{21}$ de Wagenaar, B., S. Dekker, H. L. de Boer, J. G. Bomer, W. Olthuis, A. van den Berg, and L. I. Segerink. Towards 
microfluidic sperm refinement: impedance-based analysis and sorting of sperm cells. Lab Chip 16:1514-1522, 2016.

${ }^{22}$ DeBaun, M. R., E. L. Niemitz, and A. P. Feinberg. Association of in vitro fertilization with BeckwithWiedemann syndrome and epigenetic alterations of LIT1 and H19. Am. J. Hum. Genet. 72:156-160, 2003.

${ }^{23}$ Dejonge, C. J., C. L. R. Barratt, E. Radwanska, and I. D. Cooke. The acrosome reaction-inducing effect of human follicular and oviductal fluid. J. Androl. 141:359-365, 1993.

${ }^{24}$ Denissenko, P., V. Kantsler, D. J. Smith, and J. KirkmanBrown. Human spermatozoa migration in microchannels reveals boundary-following navigation. Proc. Natl. Acad. Sci. 109:8007-8010, 2012.

${ }^{25}$ Di Santo, M., N. Tarozzi, M. Nadalini, and A. Borini. Human sperm cryopreservation: update on techniques, effect on DNA integrity, and implications for ART. $A d v$. Urol. 20:15, 2012.

${ }^{26}$ Druart, X., J. Cognié, G. Baril, F. Clément, J. L. Dacheux, and J. L. Gatti. In vivo imaging of in situ motility of fresh and liquid stored ram spermatozoa in the ewe genital tract. Reproduction 138:45-53, 2009.

${ }^{27} \mathrm{El} \mathrm{Hajj}$, N., and T. Haaf. Epigenetic disturbances in in vitro cultured gametes and embryos: implications for human assisted reproduction. Fertil. Steril. 99:632-641, 2013.

${ }^{28}$ Ellington, J. A., E. W. Carney, P. B. Farrell, M. E. Simkin, and R. H. Foote. Bovine 1-2-cell embryo development using a simple medium in three oviduct epithelial cell coculture systems. Biol. Reprod. 43:97-104, 1990.

${ }^{29}$ Ellington, J. E., D. P. Evenson, J. E. Fleming, R. S. Brisbois, G. A. Hiss, S. J. Broder, and R. W. Wright. Coculture of human sperm with bovine oviduct epithelial cells decreases sperm chromatin structural changes seen during culture in media alone. Fertil. Steril. 69:643-649, 1998.

${ }^{30}$ Ellington, J. E., D. P. Evenson, R. W. Wright, A. E. Jones, C. S. Schneider, G. A. Hiss, and R. S. Brisbois. Higher-quality human sperm in a sample selectively attach to oviduct (fallopian tube) epithelial cells in vitro. Fertil. Steril. 71:924-929, 1999.

${ }^{31}$ El-Sherry, T. M., M. Elsayed, H. K. Abdelhafez, and M. Abdelgawad. Characterization of rheotaxis of bull sperm using microfluidics. Integr. Biol. 6:1111-1121, 2014.

${ }^{32}$ Erikson, D. W., A. L. Way, R. P. Bertolla, D. A. Chapman, and G. J. Killian. Influence of osteopontin, casein and oviductal fluid on bovine sperm capacitation. Anim. Reprod. 4:103-112, 2007.

${ }^{33}$ Eyestone, W. H., and N. L. First. Co-culture of early cattle embryos to the blastocyst stage with oviducal tissue or in conditioned medium. J. Reprod. Fertil. 85:715-720, 1989.

${ }^{34}$ Fotheringham, S., K. Levanon, and R. Drapkin. Ex vivo culture of primary human fallopian tube epithelial cells. $J$. Vis. Exp. 3-7:e2728, 2011. doi:10.3791/2728.

${ }^{35}$ Gabler, C., S. Odau, K. Muller, J. Schon, A. Bondzio, and R. Einspanier. Exploring cumulus-oocyte-complexoviductal cell interactions: gene profiling in the bovine oviduct. J. Physiol. Pharmacol. 59(Suppl 9):29-42, 2008.

${ }^{36} \mathrm{Gad}$, A., M. Hoelker, U. Besenfelder, V. Havlicek, U. Cinar, F. Rings, E. Held, I. Dufort, M.-A. Sirard, K. Schellander, and D. Tesfaye. Molecular mechanisms and pathways involved in bovine embryonic genome activation and their regulation by alternative in vivo and in vitro culture conditions. Biol. Reprod. 87(4):100, 2012.
${ }^{37}$ Gandolfi, F., and R. M. Moor. Stimulation of early embryonic development in the sheep by co-culture with oviduct epithelial cells. J. Reprod. Fertil. 81:23-28, 1987.

${ }^{38}$ Gonçalves, R. F., A. L. Staros, and G. J. Killian. Oviductal fluid proteins associated with the bovine zona pellucida and the effect on in vitro sperm-egg binding, fertilization and embryo development. Reprod. Domest. Anim. 43:720-729, 2008.

${ }^{39}$ Gualtieri, R., V. Mollo, S. Braun, V. Barbato, I. Fiorentino, and R. Talevi. Long-term viability and differentiation of bovine oviductal monolayers: bidimensional versus three-dimensional culture. Theriogenology 78:14561464, 2012.

${ }^{40}$ Gualtieri, R., V. Mollo, S. Braun, V. Barbato, I. Fiorentino, and R. Talevi. Bovine oviductal monolayers cultured under three-dimension conditions secrete factors able to release spermatozoa adhering to the tubal reservoir in vitro. Theriogenology 79(3):429-435, 2013.

${ }^{41}$ Huang, H.-Y., H.-T. Fu, H.-Y. Tsing, H.-J. Huang, C.-J. Li, and D.-J. Yao. Motile human sperm sorting by an integrated microfluidic system. J. Nanomed. Nanotechnol. 5:199, 2014. doi:10.4172/2157-7439.1000199.

${ }^{42}$ Huang, H. Y., H. H. Shen, C. H. Tien, C. J. Li, S. K. Fan, C. H. Liu, W. S. Hsu, and D. J. Yao. Digital microfluidic dynamic culture of mammalian embryos on an Electrowetting on Dielectric (EWOD) chip. PLOS ONE 10:115, 2015.

${ }^{43}$ Huh, D., G. A. Hamilton, and D. E. Ingber. From 3D cell culture to organs-on-chips. Trends Cell Biol. 21:745-754, 2011.

${ }^{44}$ Hung, P., and S. S. Suarez. Alterations to the bull sperm surface proteins that bind sperm to oviductal epithelium. Biol. Reprod. 87:88, 2012.

${ }^{45}$ Hunter, R. H. Oviduct function in pigs, with particular reference to the pathological condition of polyspermy. Mol. Reprod. Dev. 29:385-391, 1991.

${ }^{46}$ Huntriss, J. D., and H. M. Picton. Epigenetic consequences of assisted reproduction and infertility on the human preimplantation embryo. Hum. Fertil. (Camb) 11:85-94, 2008

${ }^{47}$ Joshi, M. S. Isolation, cell culture, and characterization of oviduct epithelial cells of the cow. Microsc. Res. Technol. 31:507-518, 1995.

${ }^{48}$ Karst, A. M., and R. Drapkin. Primary culture and immortalization of human fallopian tube secretory epithelial cells. Nat. Protoc. 7:1755-1764, 2012.

${ }^{49}$ Kessler, M., K. Hoffmann, V. Brinkmann, O. Thieck, S. Jackisch, B. Toelle, H. Berger, H.-J. Mollenkopf, M. Mangler, J. Sehouli, C. Fotopoulou, and T. F. Meyer. The Notch and Wnt pathways regulate stemness and differentiation in human fallopian tube organoids. Nat. Commun. 6:8989, 2015.

${ }^{50}$ Killian, G. J. Evidence for the role of oviduct secretions in sperm function, fertilization and embryo development. Anim. Reprod. Sci. 82-83:141-153, 2004.

${ }^{51}$ Killian, G. Physiology and endocrinology symposium: evidence that oviduct secretions influence sperm function: A retrospective view for livestock. J. Anim. Sci. 89:13151322, 2011.

${ }^{52}$ Kim, M. S., C. Y. Bae, G. Wee, Y. M. Han, and J. K. Park. A microfluidic in vitro cultivation system for mechanical stimulation of bovine embryos. Electrophoresis 30:3276-3282, 2009.

${ }^{53}$ King, R. S., S. H. Anderson, and G. J. Killian. Effect of bovine oviductal estrus-associated protein on the ability of 
sperm to capacitate and fertilize oocytes. J. Androl. 15:468-478, 1994.

${ }^{54}$ King, S. M., T. S. Hilliard, L. Y. Wu, R. C. Jaffe, A. T. Fazleabas, and J. E. Burdette. The impact of ovulation on fallopian tube epithelial cells: evaluating three hypotheses connecting ovulation and serous ovarian cancer. Endocr. Relat. Cancer 18:627-642, 2011.

${ }^{55}$ King, S. M., S. Quartuccio, T. S. Hilliard, K. Inoue, and J. E. Burdette. Alginate hydrogels for three-dimensional organ culture of ovaries and oviducts. J. Vis. Exp. 52:e2804, 2011. doi:10.3791/2804.

${ }^{56}$ Knowlton, S. M., M. Sadasivam, and S. Tasoglu. Microfluidics for sperm research. Trends Biotechnol. 33:221-229, 2016

${ }^{57}$ Kölle, S. Live cell imaging of the oviduct. Methods Enzymol. 506:415-423, 2012.

${ }^{58}$ Kölle, S., S. Dubielzig, S. Reese, A. Wehrend, P. König, and W. Kummer. Ciliary transport, gamete interaction, and effects of the early embryo in the oviduct: ex vivo analyses using a new digital videomicroscopic system in the cow. Biol. Reprod. 81:267-274, 2009.

${ }^{59}$ Kölle, S., S. Reese, and W. Kummer. New aspects of gamete transport, fertilization, and embryonic development in the oviduct gained by means of live cell imaging. Theriogenology 73:786-795, 2010.

${ }^{60}$ Kumaresan, A., M. R. Ansari, and A. Garg. Modulation of post-thaw sperm functions with oviductal proteins in buffaloes. Anim. Reprod. Sci. 90:73-84, 2016.

${ }^{61}$ La Spina, F. A., L. C. Puga Molina, A. Romarowski, A. M. Vitale, T. L. Falzone, D. Krapf, N. Hirohashi, and M. G. Buffone. Mouse sperm begin to undergo acrosomal exocytosis in the upper isthmus of the oviduct. Dev. Biol. 411(2):172-182, 2016.

${ }^{62}$ Lai, D., S. Takayama, and G. D. Smith. Recent microfluidic devices for studying gamete and embryo biomechanics. J. Biomech. 48:1671-1678, 2015.

${ }^{63}$ Lamy, J., V. Labas, G. Harichaux, G. Tsikis, P. Mermillod, and M. Saint-Dizier. Regulation of the bovine oviductal fluid proteome. Reproduction 152:629-644, 2016.

${ }^{64}$ Lamy, J., P. Liere, A. Pianos, F. Aprahamian, P. Mermillod, and M. Saint-Dizier. Steroid hormones in bovine oviductal fluid during the estrous cycle. Theriogenology 86:1409-1420, 2015.

${ }^{65}$ Leemans, B., B. M. Gadella, T. A. E. Stout, S. Heras, K. Smits, M. Ferrer-Buitrago, E. Claes, B. Heindryckx, W. H. De Vos, H. Nelis, M. Hoogewijs, and A. Van Soom. Procaine induces cytokinesis in horse oocytes via a phdependent mechanism. Biol. Reprod. 93:23, 2015.

${ }^{66}$ Leemans, B., B. M. Gadella, T. A. E. Stout, E. Sostaric, C. De Schauwer, H. M. Nelis, M. Hoogewijs, and A. Van Soom. Combined albumin and bicarbonate adversely affects equine sperm-oviduct binding. Reproduction 151:313-330, 2016.

${ }^{67} \mathrm{Li}$, T., T. H. Vu, G. A. Ulaner, E. Littman, J. Q. Ling, H. L. Chen, J. F. Hu, B. Behr, L. Giudice, and A. R. Hoffman. IVF results in de novo DNA methylation and histone methylation at an Igf2-H19 imprinting epigenetic switch. Mol. Hum. Reprod. 11:631-640, 2005.

${ }^{68}$ Lloyd, R. E., R. Romar, C. Matás, A. Gutiérrez-Adán, W. V. Holt, and P. Coy. Effects of oviductal fluid on the development, quality, and gene expression of porcine blastocysts produced in vitro. Reproduction 137:679-687, 2009.
${ }^{69}$ Macdonald, N. P., F. Zhu, C. J. Hall, J. Reboud, P. S. Crosier, E. E. Patton, D. Wlodkowic, and J. M. Cooper. Assessment of biocompatibility of 3D printed photopolymers using zebrafish embryo toxicity assays. Lab Chip 16:291-297, 2016.

${ }^{70}$ Maillo, V., P. O. Gaora, N. Forde, U. Besenfelder, V. Havlicek, G. W. Burns, T. E. Spencer, A. Gutierrez-Adan, P. Lonergan, and D. Rizos. Oviduct-embryo interactions in cattle: two-way traffic or a one-way street? Biol. Reprod. 92:144, 2015.

${ }^{71}$ Maillo, V., R. Lopera-Vasquez, M. Hamdi, A. GutierrezAdan, P. Lonergan, and D. Rizos. Maternal-embryo interaction in the bovine oviduct: evidence from in vivo and in vitro studies. Theriogenology 86:443-450, 2016.

${ }^{72}$ Malda, J. 52 Use of transwell cell culture and 3-dimensional printing technology to develop an in vitro bovine oviduct. Reprod. Fertil. Dev. 28:130, 2016.

${ }^{73} \mathrm{Mcnutt}, \mathrm{T}$., and G. Killian. Influence of bovine follicular and oviduct fluids on sperm capacitation in vitro. $J$. $A n$ drol. 12:244-252, 1991.

${ }^{74}$ McNutt, T., L. Rogowski, R. Vasilatos-Younken, and G. Killian. Adsorption of oviductal fluid proteins by the bovine sperm membrane during in vitro capacitation. Mol. Reprod. Dev. 33:313-323, 1992.

${ }^{75}$ Menezo, Y., and P. Guerin. The mammalian oviduct: biochemistry and physiology. Eur. J. Obstet. Gynecol. Reprod. Biol. 73:99-104, 1997.

${ }^{76}$ Ménézo, Y., P. Guérin, and K. Elder. The oviduct: a neglected organ due for re-assessment in IVF. Reprod. Biomed. Online 30:233-240, 2015.

${ }^{77}$ Miessen, K., S. Sharbati, R. Einspanier, and J. Schoen. Modelling the porcine oviduct epithelium: a polarized in vitro system suitable for long-term cultivation. Theriogenology 76:900-910, 2011.

${ }^{78}$ Mizuno, J., S. Ostrovidov, Y. Sakai, T. Fujii, H. Nakamura, and $\mathrm{H}$. Inui. Human ART on chip: improved human blastocyst development and quality with IVF-chip. Fertil. Steril. 88:S101, 2007.

${ }^{79}$ Monaco, E., B. Gasparrini, L. Boccia, A. De Rosa, L. Attanasio, L. Zicarelli, and G. Killian. Effect of osteopontin (OPN) on in vitro embryo development in cattle. Theriogenology 71:450-457, 2009.

${ }^{80}$ Mondéjar, I., I. Martínez-Martínez, M. Avilés, and P. Coy. Identification of potential oviductal factors responsible for zona pellucida hardening and monospermy during fertilization in mammals. Biol. Reprod. 89:67, 2013.

${ }^{81}$ Morales, P., M. Salgado, and M. Villalón. Fertilization and early embryology: sperm interaction with human oviductal cells in vitro. Hum. Reprod. 11(7):1504-1509, 1996.

${ }^{82}$ Murphy, S. V., and A. Atala. 3D bioprinting of tissues and organs. Nat. Biotechnol. 32:773-785, 2014.

${ }^{83}$ Murray, M. K. Epithelial lining of the sheep ampulla oviduct undergoes pregnancy-associated morphological changes in secretory status and cell height. Biol. Reprod. 53:653-663, 1995.

${ }^{84}$ Nancarrow, C. D., and J. L. Hill. Co-culture, oviduct secretion and the function of oviduct-specific glycoproteins. Cell Biol. Int. 18:1105-1114, 1994.

${ }^{85}$ Nedambale, T. L., A. Dinnys, W. Groen, J. R. Dobrinsky, X. C. Tian, and X. Yang. Comparison on in vitro fertilized bovine embryos cultured in KSOM or SOF and cryopreserved by slow freezing or vitrification. Theriogenology 62:437-449, 2004. 
${ }^{86}$ Nelis, H., K. D'Herde, K. Goossens, L. Vandenberghe, B. Leemans, K. Forier, K. Smits, K. Braeckmans, L. Peelman, and A. Van Soom. Equine oviduct explant culture: a basic model to decipher embryo-maternal communication. Reprod. Fertil. Develop. 26(7):954-966, 2014.

${ }^{87}$ Nelissen, E. C. M., J. C. M. Dumoulin, F. Busato, L. Ponger, L. M. Eijssen, J. L. H. Evers, J. Tost, and A. P. A. van Montfoort. Altered gene expression in human placentas after IVF/ICSI. Hum. Reprod. 29:2821-2831, 2014.

${ }^{88} \mathrm{Ng}$, A., S. Tan, G. Singh, P. Rizk, Y. Swathi, T. Z. Tan, R. Y. Huang, M. Leushacke, and N. Barker. Lgr5 marks stem/progenitor cells in ovary and tubal epithelia. Nat. Cell Biol. 16:745-757, 2014.

${ }^{89}$ Paik, D. Y., D. M. Janzen, A. M. Schafenacker, V. S. Velasco, M. S. Shung, D. Cheng, J. Huang, O. N. Witte, and S. Memarzadeh. Stem-like epithelial cells are concentrated in the distal end of the fallopian tube: a site for injury and serous cancer initiation. Stem Cells 30:2487-2497, 2012.

${ }^{90}$ Pampaloni, F., E. G. Reynaud, and E. H. K. Stelzer. The third dimension bridges the gap between cell culture and live tissue. Nat. Rev. Mol. Cell Biol. 8:839-845, 2007.

${ }^{91}$ Parrish, J. J., J. L. Susko-Parrish, R. R. Handrow, M. M. Sims, and N. L. First. Capacitation of bovine spermatozoa by oviduct fluid. Biol. Reprod. 40:1020-1025, 1989.

${ }^{92}$ Pollard, J. W., C. Plante, W. A. King, P. J. Hansen, K. J. Betteridge, and S. S. Suarez. Fertilizing capacity of bovine sperm may be maintained by binding of oviductal epithelial cells. Biol. Reprod. 44(1):102-107, 1991.

${ }^{93}$ Rajagopal, M., T. L. Tollner, W. E. Finkbeiner, G. N. Cherr, and J. H. Widdicombe. Differentiated structure and function of primary cultures of monkey oviductal epithelium. Vitr. cell. Dev. Biol. 42:248-254, 2006.

${ }^{94}$ Reischl, J., K. Prelle, H. Schöl, C. Neumüller, R. Einspanier, F. Sinowatz, and E. Wolf. Factors affecting proliferation and dedifferentiation of primary bovine oviduct epithelial cells in vitro. Cell Tissue Res. 296:371383, 1999.

${ }^{95}$ Rodríguez, C., and G. Killian. Identification of ampullary and isthmic oviductal fluid proteins that associate with the bovine sperm membrane. Animal reproduction science 54:1-12, 1998.

${ }^{96}$ Rodriguez-Martinez, H. Role of the oviduct in sperm capacitation. Theriogenology 68:138-146, 2007.

${ }^{97}$ Salilew-Wondim, D., E. Fournier, M. Hoelker, M. SaeedZidane, E. Tholen, C. Looft, C. Neuhoff, U. Besenfelder, V. Havlicek, F. Rings, D. Gagné, M. A. Sirard, C. Robert, H. A. Shojaei Saadi, K. Gad, K. Schellander, and D. Tesfaye. Genome-wide DNA methylation patterns of bovine blastocysts developed in vivo from embryos completed different stages of development in vitro. PLOS ONE 10:1-31, 2015.

${ }^{98}$ Santos, F., L. Hyslop, P. Stojkovic, C. Leary, A. Murdoch, W. Reik, M. Stojkovic, M. Herbert, and W. Dean. Evaluation of epigenetic marks in human embryos derived from IVF and ICSI. Hum. Reprod. 25:2387-2395, 2010.

${ }^{99}$ Scherr, T., G. L. Knapp, A. Guitreau, D. S.-W. Park, T. Tiersch, K. Nandakumar, and W. T. Monroe. Microfluidics and numerical simulation as methods for standardization of zebrafish sperm cell activation. Biomed. Microdevices 17:1-10, 2015.

${ }^{100}$ Schnorr, J. A., S. J. Muasher, and H. W. Jones. Evaluation of the clinical efficacy of embryo cryopreservation. Mol. Cell. Endocrinol. 169:85-89, 2000.

${ }^{101}$ Schoen, J., A. Bondzio, K. Topp, and R. Einspanier. Establishment and characterization of an adherent pure epithelial cell line derived from the bovine oviduct. Theriogenology 69:536-545, 2008.

${ }^{102}$ Sessions-Bresnahan, D. R., J. K. Graham, and E. M. Carnevale. Validation of a heterologous fertilization assay and comparison of fertilization rates of equine oocytes using invitro fertilization, perivitelline, and intracytoplasmic sperm injections. Theriogenology 82:274-282, 2014.

${ }^{103}$ Shalgi, R., and D. M. Phillips. Motility of rat spermatozoa at the site of fertilization. Biol. Reprod. 39:1207-1213, 1988.

${ }^{104}$ Sostaric, E., S. J. Dieleman, C. H. A. van de Lest, B. Colenbrander, P. L. A. M. Vos, N. Garcia-Gil, and B. M. Gadella. Sperm binding properties and secretory activity of the bovine oviduct immediately before and after ovulation. Mol. Reprod. Dev. 75:60-74, 2008.

${ }^{105}$ Squires, E. L. Semen cryopreservation - challenges and perspectives. Rev. Bras. Reprod. Anim. 37:136-139, 2013.

${ }^{106}$ Steinhauer, N., A. Boos, and A. R. Günzel-Apel. Morphological changes and proliferative activity in the oviductal epithelium during hormonally defined stages of the oestrous cycle in the bitch. Reprod. Domest. Anim. 39:110-119, 2004.

${ }^{107}$ Suarez, S. S. Sperm transport and motility in the mouse oviduct: observations in situ. Biol. Reprod. 36:203-210, 1987.

${ }^{108}$ Suarez, S. S. Mammalian sperm interactions with the female reproductive tract. Cell Tissue Res. 363:185-194, 2016.

${ }^{109}$ Suarez, S. S., and M. Wu. Microfluidic devices for the study of sperm migration. Mol. Hum. Reprod. 2016. doi: 10.1093/molehr/gaw039.

${ }^{110}$ Sudano, M. J., D. M. Paschoal, and T. da Silva. Rascado, L. C. O. Magalh??es, L. F. Crocomo, J. F. de Lima-Neto, and F. da Cruz Landim-Alvarenga. Lipid content and apoptosis of in vitro-produced bovine embryos as determinants of susceptibility to vitrification. Theriogenology 75:1211-1220, 2011.

${ }^{111}$ Swain, J. E., and G. D. Smith. Advances in embryo culture platforms: novel approaches to improve preimplantation embryo development through modifications of the microenvironment. Hum. Reprod. Update 17:541-557, 2011.

${ }^{112}$ Talevi, R., and R. Gualtieri. Molecules involved in spermoviduct adhesion and release. Theriogenology 73:796-801, 2010.

${ }^{113}$ Thompson, J. G., K. L. Kind, C. T. Roberts, S. A. Robertson, and E. Al. Epigenetic risks related to assisted reproductive technologies: short-and long-term consequences for the health of children conceived through assisted reproduction. Hum. Reprod. 17:2783-2786, 2002.

${ }^{114}$ Tse, P. K., Y. L. Lee, W. N. Chow, J. M. C. Luk, K. F. Lee, and W. S. B. Yeung. Preimplantation embryos cooperate with oviductal cells to produce embryotrophic inactivated complement-3b. Endocrinology 149:1268-1276, 2008.

${ }^{115}$ Ulbrich, S. E., K. Zitta, S. Hiendleder, and E. Wolf. In vitro systems for intercepting early embryo-maternal cross-talk in the bovine oviduct. Theriogenology 73:802816, 2010.

${ }^{116}$ Van Soom, A., L. Vandaele, L. J. Peelman, K. Goossens, and A. Fazeli. Modeling the interaction of gametes and embryos with the maternal genital tract: from in vivo to in silico. Theriogenology 73:828-837, 2010.

${ }^{117}$ Ventura-Juncá, P., I. Irarrázaval, A. J. Rolle, J. I. Gutiérrez, R. D. Moreno, and M. J. Santos. In vitro fertil- 
ization (IVF) in mammals: epigenetic and developmental alterations. Scientific and bioethical implications for IVF in humans. Biol. Res. 48:68, 2015.

${ }^{118}$ Verhage, H. G., A. T. Fazleabas, P. A. Mavrogianis, M. B. O'Day-Bowman, K. M. Donnelly, E. B. Arias, and R. C. Jaffe. The baboon oviduct: characteristics of an oestradiol-dependent oviduct-specific glycoprotein. Hum. Reprod. Update 3:541-552, 1997.

${ }^{119}$ Villamil, P. R., D. Lozano, J. M. Oviedo, F. L. Ongaratto, and G. A. Bo. Developmental rates of in vivo and in vitro produced bovine embryos cryopreserved in EG based solutions by slow freezing or solid surface vitrification. Anim. Reprod. 9:86-92, 2012.

${ }^{120}$ Wang, Y., A. Sacchetti, M. R. van Dijk, M. van der Zee, P. H. van der Horst, R. Joosten, C. W. Burger, J. A. Grootegoed, L. J. Blok, and R. Fodde. Identification of Quiescent, Stem-Like Cells in the Distal Female Reproductive Tract. PLoS ONE 7:e40691, 2012.
${ }^{121}$ Xie, Y. Shear Stress Induces Preimplantation Embryo Death That Is Delayed by the Zona Pellucida and Associated with Stress-Activated Protein Kinase-Mediated Apoptosis. Biol. Reprod. 75:45-55, 2006.

${ }^{122}$ Yamanouchi, H., T. Umezu, and Y. Tomooka. Reconstruction of oviduct and demonstration of epithelial fate determination in mice. Biol. Reprod. 82:528-533, 2010.

${ }^{123}$ Yaniz, J. L., F. Lopez-Gatius, and R. H. F. Hunter. Scanning electron microscopic study of the functional anatomy of the porcine oviductal mucosa. Anat. Histol. Embryol. 35:28-34, 2006.

${ }^{124}$ Zhang, B., T. L. Yin, and J. Yang. A novel microfluidic device for selecting human sperm to increase the proportion of morphologically normal, motile sperm with uncompromised DNA integrity. Anal. Methods 7:59815988, 2015. 